AWEJ for Translation \& Literary Studies, Volume3, Number3. August 2019

DOI: http://dx.doi.org/10.24093/awejtls/vol3no3.12

Pp.151-164

\title{
Domesticating the Text: Collocation Patterns and their Significance in the Translated Text
}

\author{
Mansour K. Thajeel Aldanani \\ Department of Physics \\ Faculty of Science, University of Sumer \\ Thi-qar, Iraq
}

\begin{abstract}
:
This paper is an attempt to examine, through examples, the significance of collocation patterns for the translated text. To prove this, a corpus is collected from two translated articles in National Geographic magazine, Arabic version and their English counterparts. The given examples show that a great abundance of collocations patterns surfaced in the Arabic target texts (TT). The results obtained are used to argue that these patterns have cohesive, coherent, and aesthetic functions in the target text. To produce a translation that can read as much fluently and naturally as possible, professional translators work painstakingly to domesticate the source text as the magazine, in its Arabic version, is targeting different readership and culture. To accomplish their task, translators draw on their language competence especially 'collocation competence' as a domesticating strategy.

Keywords: collocations patterns, English collocations, Arabic collocations, fluency, naturalness, domesticating strategy.

Cites as: Aldanani, M. K. T. (2019). Domesticating the Text: Collocation Patterns and their Significance in the Translated Text. Arab World English Journal for Translation \& Literary Studies, 3 (3) 161-174. DOI: http://dx.doi.org/10.24093/awejtls/vol3no3.12
\end{abstract}

